\title{
Patterns of use for brand-name versus generic oral bisphosphonate drugs in Ontario over a 13-year period: a descriptive study
}

\author{
Lisa-Ann Fraser MD MSc, Jordan M. Albaum MSc, Mina Tadrous PharmD MS, Andrea M. Burden BSc, \\ Salimah Z. Shariff PhD, Suzanne M. Cadarette PhD
}

\section{Abstract}

Background: Bisphosphonates are the first-line therapy for the treatment of osteoporosis. In the province of Ontario, the Ontario Drug Benefit Program funds medications for patients aged 65 years and older. The Ontario Drug Benefit Program has a generic substitution policy that requires lower-cost generic drugs to be dispensed when they are available. However, there is controversy surrounding the efficacy and tolerability of generic bisphosphonates. The objective of this study was to describe patterns in the use of brand-name versus generic formulations when dispensing oral bisphosphonate over a 13-year period.

Methods: We identified all osteoporotic preparations for alendronate and risedronate that were dispensed through the Ontario Drug Benefit Program from 2001 to 2014. We stratified our sample into community-dwelling residents and residents in long-term care facilities. The number of prescriptions dispensed per month were plotted to illustrate trends over time.

Results: We found a rapid switch from brand-name to generic bisphosphonate equivalents immediately after the generic became available on the Ontario Drug Benefit formulary, with generics accounting for $>88 \%$ of dispensed drug within 2 months. We also observed a reduction in the number of generic drugs dispensed each time a new brand-name alternative (e.g., monthly risedronate, weekly alendronate plus vitamin D) was introduced to the formulary. The dispensing trends were similar in the community and longterm care settings.

Interpretation: The Ontario Drug Benefit Program generic substitution policy resulted in rapid uptake of generic oral bisphosphonates among seniors in Ontario. However, there was a switch away from generic medications to new brand-name alternatives whenever they were introduced to the formulary. Therefore, some patients continued to use brand-name bisphosphonate despite the availability of generic options.

\section{Tisis} n Canada, the costs of outpatient prescription medications are increasing. Medication costs rose from $\$ 8$ billion in 1998 to $\$ 19$ billion in 2007, an average increase of $10.1 \%$ per year. ${ }^{1}$ Different policies and practices have attempted to control and decrease medication costs, with varying results. ${ }^{2}$ The use of less expensive generic versions of brand-name medications is an opportunity to contain costs. In Canada, generic drug prices are regulated, and most are set at $25 \%-56 \%$ of the proprietary drug cost. ${ }^{1}$ As such, generic drugs account for $63 \%$ of all prescriptions in Canada but only $24 \%$ of annual prescription drug costs. ${ }^{3}$

Oral bisphosphonates are considered first-line therapy for the treatment of osteoporosis. ${ }^{4}$ In Canada, alendronate and risedronate are prescribed most often. ${ }^{5}$ Both medications have proven efficacy in fracture prevention and are generally welltolerated. ${ }^{6-9}$ In the province of Ontario, the Ontario Drug Benefit (ODB) Program funds prescription medication for patients aged 65 years and older. The ODB's generic substitu- tion policy automatically switches most oral bisphosphonate therapy to the lower-cost generic product, once a generic equivalent is available on the drug formulary. The Drug Interchangeability and Dispensing Fee Act, enacted in 1990 in Ontario, mandates that if a generic and a brand-name drug are available, ODB will only pay for the lower-cost version. ${ }^{10}$ Therefore, the pharmacy will dispense the lower-cost generic

Competing interests: Mina Tadrous has received a Frederick Banting and Charles Best Graduate Scholarship from the Canadian Institute for Health Information (CIHR). Lisa-Ann Fraser has received speaker fees from Amgen. No competing interests were declared by the other authors.

This article has been peer reviewed.

Correspondence to: Lisa-Ann Fraser, Lisaann.Fraser@sjhc.london.on.ca CMAJ Open 2015. DOI:10.9778/cmajo.20140090 
drug (regardless of the drug name on the prescription) and must inform the patient of the substitution. The only exception to this rule, whereby ODB will pay for the higher-cost brand-name drug, is when a patient has had a documented adverse reaction to the generic drug. In this situation, the patient's physician must specify that the patient requires the brand-name version of the drug on the prescription, and it must be accompanied by a completed Health Canada adverse reaction reporting form. ${ }^{11}$ Patients may independently choose to receive the brand-name drug, but they must pay for the excess cost.

There is some controversy as to the efficacy and tolerability of generic bisphosphonates, and several reports documented declines in treatment adherence when patients are switched from brand-name to generic equivalents. ${ }^{12,13}$ Poor adherence to bisphosphonate therapy leads to reduced drug effectiveness and has important implications for generic drug cost-effectiveness and the societal burden of osteoporosis and fracture. Because of existing concerns about generic bisphosphonates, many patients and physicians prefer the brandname product. ${ }^{14}$ To assess the effectiveness of the ODB generic substitution policy, we examined dispensing patterns for all oral bisphosphonate medications over a 13-year period (2001-2014).

\section{Methods}

\section{Setting}

Ontario has a population of about 13 million, of which $14.6 \%$ are aged 65 years or older. ${ }^{15}$ Using data from ODB, we identified all prescriptions for alendronate and risedronate dispensed to patients aged 65 years and older from Jan. 1, 2001, to Mar. 31, 2014. The year 2001 was chosen as the initial date to capture prescribing habits for a short period before the introduction of the first generic bisphosphonate to the formulary in 2003.

\section{Design}

We sought to describe bisphosphonate dispensing trends over time and to investigate the real-world effectiveness of a generic substitution policy. Given that the substitution policy is mandatory, there should be $100 \%$ substitution with the generic equivalent for alloral bisphosphonate prescriptions quickly after the generic version was added to the formulary. All prescriptions dispensed for alendronate and risedronate (at doses used to treat osteoporosis) were identified in the ODB program database. Ibandronate was not examined because it is not available in Canada. Etidronate was not examined because it is not currently considered a first-line therapy for osteoporosis treatment. We excluded bisphosphonate doses used to treat conditions other than osteoporosis. Patients who reside in long-term care facilities are identified in the ODB program database by a mandatory field that must be filled by the pharmacist at the time the drug is dispensed to the patient. Because prescription patterns may differ between community and long-term care settings, ${ }^{16}$ we stratified our sample into these 2 subpopulations

\section{Sources of data}

The ODB program database is an accurate record of drugs dispensed in Ontario to patients who are aged 65 years and older, with a previously recorded error rate of $<1 \% .{ }^{17}$ Relevant datasets were held securely in a linked form, with all personal identifiers removed or encoded, at the Institute for Clinical Evaluative Sciences in Ontario.

\section{Statistical analysis}

The number of prescriptions dispensed per month were calculated and plotted to identify trends over time.

\section{Ethics approval}

The study was approved by the Research Ethics Board at Sunnybrook Health Sciences Centre, Toronto, Ontario.

\section{Results}

Our analysis showed that 19369381 prescriptions for oral bisphosphonates were dispensed to patients aged 65 years and older in Ontario over the 13-year period: 14599522 prescriptions were dispensed to community-dwelling patients, and 4769859 prescriptions were dispensed to patients in long-term care facilities. The dates when each generic bisphosphonate was first dispensed from the ODB formulary are shown in Table 1. Figures 1 and 2 show the trends in oral bisphosphonate dispensing for the study period. In the community, daily brand-name alendronate and daily brand-name risedronate were the first to be used. In 2003, when weekly brand-name risedronate and alendronate became available, the number of oral bisphosphonate prescriptions increased, with a decline in prescriptions for the daily use variety (Figure 1). A rapid switch occurred from brand-name to generic equivalent for alendronate in 2005 and for risedronate in 2010. In both cases, > 88\% of the prescriptions dispensed were for the generic drug within 2 months of the generic being available, and $>95 \%$ of the prescriptions dispensed were for the generic drug within 3 months (Table 2). A similar, although somewhat faster, uptake was seen in the long-term care setting: > $93 \%$ of the prescriptions for weekly alendronate and risedronate were dispensed in the generic form within 2 months of the introduction of the generic variety and $>98 \%$ of the prescriptions by 3 months

\begin{tabular}{|ll|}
\hline $\begin{array}{l}\text { Table 1: Dates when the generic } \\
\text { bisphosphonates were first dispensed in Ontario } \\
\text { by the ODB formulary }\end{array}$ \\
\hline Generic bisphosphonate & \multicolumn{1}{c|}{ Date } \\
\hline Daily alendronate & Sept. 2003 \\
\hline Weekly alendronate & July 2005 \\
\hline Daily risedronate & Apr. 2010 \\
\hline Weekly risedronate & Apr. 2010 \\
\hline Monthly risedronate & June 2012 \\
\hline Weekly alendronate + vitamin D & Jan. 2014 \\
\hline Note: ODB = Ontario Drug Benefit. & \\
\hline
\end{tabular}




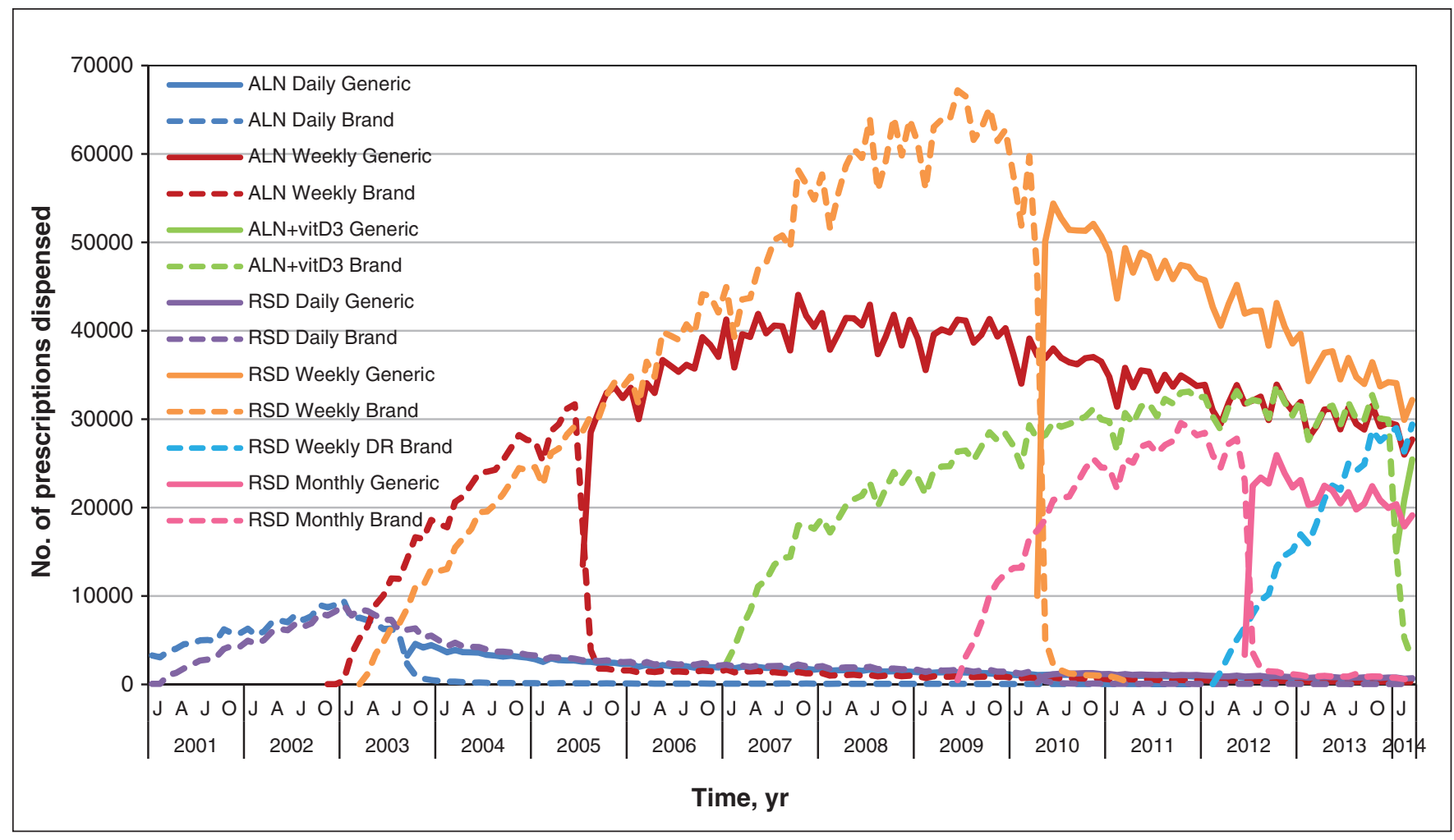

Figure 1: Number of brand-name and generic bisphosphonate prescriptions dispensed from pharmacies to patients aged 65 years and older who lived in the community. $A L N=$ alendronate, vitD3 = vitamin D3, RSD = risedronate, $D R=$ delayed release,$C a=c a l c i u m$.

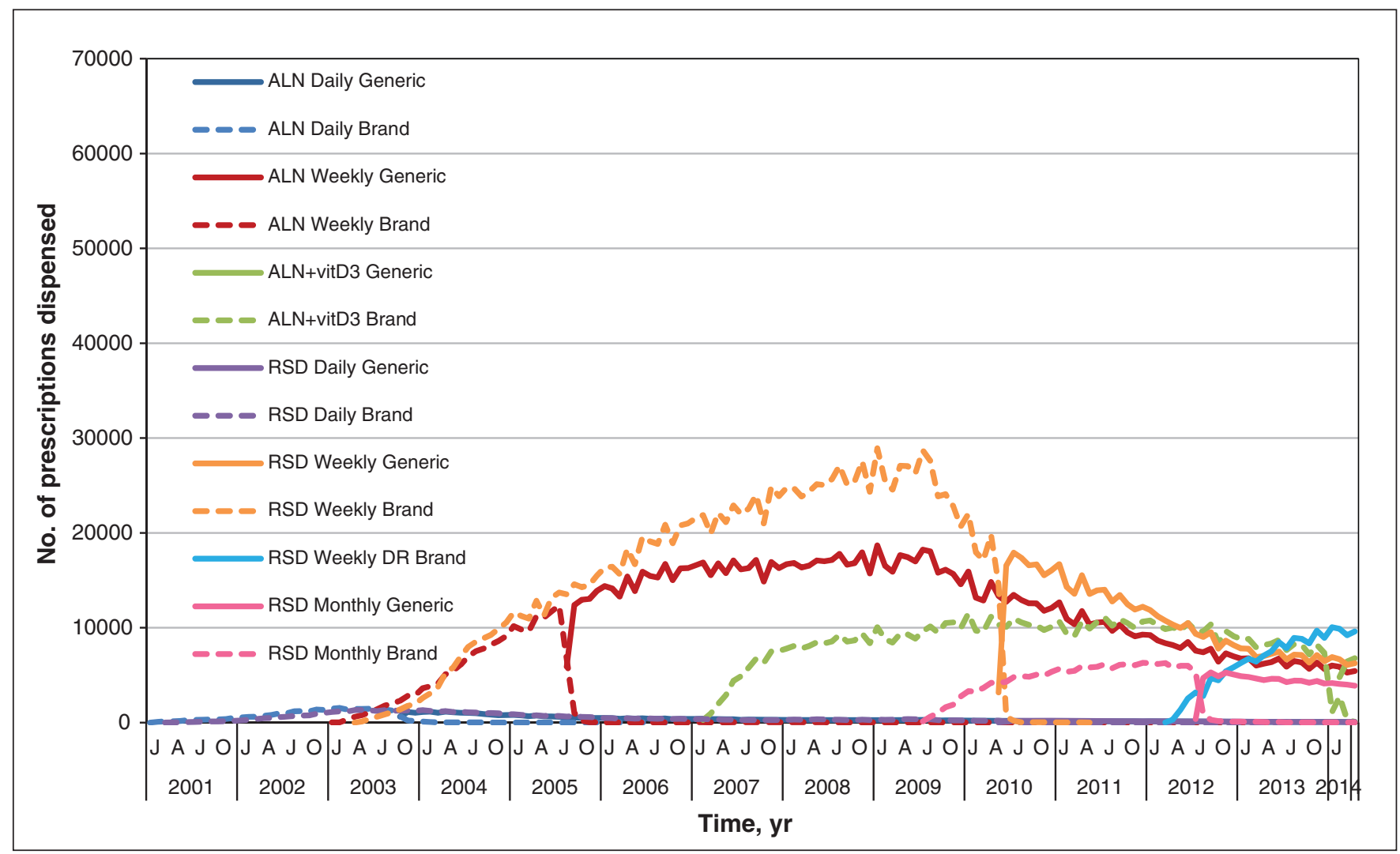

Figure 2: Number of brand-name and generic bisphosphonate prescriptions dispensed from pharmacies to patients aged 65 years and older who lived in a long-term care facility. ALN = alendronate, vitD3 = vitamin D3, RSD = risedronate, DR = delayed release, Ca $=$ calcium . 
after the introduction of the generic equivalent. A monthly brand-name risedronate was also replaced quickly by the generic equivalent when it became available in 2012. Similarly, this switch occurred for the brand-name combination pill of alendronate plus cholecalciferol in 2014.

Following the introduction of the generic alternatives, small proportions of the brand-name medications continued to be dispensed. A reduction in the number of generic drugs dispensed each time a new brand-name alternative was introduced to the market was noted: there was a decrease in generic alendronate when brand-name alendronate plus cholecalciferol became available. Similarly, there was a decrease in generic weekly risedronate when monthly brand-name risedronate became available, and again when the new delayedrelease form of brand-name risedronate was listed on the provincial drug formulary. The dispensing trends were similar in the community and in long-term care.

\section{Interpretation}

\section{Main findings}

In this large population-based study, we found a rapid switch in pharmacy dispensing of brand-name oral bisphosphonates used for osteoporosis treatment to the generic equivalent when it became available. This provides evidence of the effectiveness of the automatic generic substitution policy used in the ODB program. However, despite this policy, there was a small population of patients taking bisphosphonates who continued to use the brand-name drug. Similarly, there was a switch away from generic drugs to new brand-name drugs when they were introduced to the formulary.

\section{Comparison with other studies}

Cost containment of health care expenses is an important issue, and multiple strategies aimed at controlling drug costs have been employed. However, a 2006 Cochrane Review identified only a handful of high-quality studies that examined some of these practices. ${ }^{2}$ In the review, the use of reference pricing was found to be somewhat effective at decreasing cost by increasing the dispensing of less costly drugs; however, the study results were mixed. Similarly, the use of index pricing provided a small decrease in drug cost but was only featured in a single study. Our study provides evidence that an automatic generic substitution policy, when feasible, is a rapid and effective way to change dispensing patterns. Currently, $45 \%$ of all drugs dispensed by pharmacies in Canada and most drugs used in hospital are generics. ${ }^{18}$ In the United States, generic drug use resulted in \$1.2 trillion in savings to the health care system from 2003 to $2012 .{ }^{19}$ Savings increased by an average of $17 \%$ per year since 2007 and are expected to grow exponentially as multiple high-use drug patents will expire in the near future. ${ }^{19}$

The observed trend of a decrease in the dispensing of generic drugs when a new brand-name drug was introduced may simply be the result of preferred consumption of the new, more convenient brand-name drug. For instance, monthly brand-name risedronate needs to be taken less frequently than weekly risedronate. Similarly, delayed-release brand-name risedronate can be taken with food, whereas weekly risedronate cannot. However, a bias against generic drugs and a preference for brand-name drugs have been well-described. ${ }^{14}$ Therefore, some of the shift from generic formulations to newer brand alternatives may reflect an effort to avert the generic substitution policy.

Health Canada is responsible for ensuring the safety, efficacy and quality of all generic drugs used in Canada. The amount of active medical ingredient in the generic drugs must be the same as in the brand-name equivalent, but other nonmedical ingredients can be different. Similarly, in the United States, generic medications must be approved by the US Food and Drug Administration (FDA) and must meet criteria for identity, strength, quality, purity and potency. ${ }^{20}$ To obtain US FDA approval for a generic drug, multiple tests must be done to show that the generic can be used interchangeably with the brand-name drug. Despite efforts to ensure interchangeability, differences between brand-name and generic drugs have been observed when used in practice. One issue is that the fillers and colour may be different in the generic drugs. This alteration in drug appearance can lead to patients not recog-

\begin{tabular}{|c|c|c|c|c|c|c|}
\hline \multirow[b]{2}{*}{ Generic bisphosphonate } & \multicolumn{3}{|c|}{$\begin{array}{l}\text { Percentage of total drugs } \\
\text { dispensed to patients in the } \\
\text { community }\end{array}$} & \multicolumn{3}{|c|}{$\begin{array}{l}\text { Percentage of total drugs } \\
\text { dispensed to patients in } \\
\text { long-term care facilities }\end{array}$} \\
\hline & 1 st mo & 2nd mo & 3rd mo & 1 st mo & 2nd mo & 3rd mo \\
\hline Daily alendronate & 59 & 67 & 81 & 48 & 83 & 88 \\
\hline Weekly alendronate & 43 & 88 & 95 & 47 & 93 & 98 \\
\hline Daily risedronate & 15 & 73 & 85 & 7 & 37 & 83 \\
\hline Weekly risedronate & 18 & 91 & 96 & 18 & 96 & 99 \\
\hline Monthly risedronate & 13 & 86 & 93 & 6 & 84 & 95 \\
\hline Weekly alendronate + vitamin D & 51 & 80 & 90 & 64 & 95 & 99 \\
\hline
\end{tabular}


nizing their medication. ${ }^{21,22} \mathrm{~A}$ recent study that looked at statin and $\beta$-blocker use by patients after discharge from hospital for myocardial infarction found a 34\% increased odds of nonpersistence if there was a change in pill colour and a $66 \%$ increased odds of nonpersistence if there was a change in pill shape. ${ }^{21}$ Similar issues with nonpersistence based on generic drug colour and shape have been reported for antiepileptic drugs. ${ }^{22}$ With bisphosphonates, substantially lower drug persistence has been reported for patients who switched from a brand-name to a generic drug and for those patients who were prescribed a generic drug initially. ${ }^{12,13,23}$ The exact reason for early discontinuation of generic therapy is not known; however, there may be additional issues with the generic forms of alendronate and risedronate, such as increased gastrointestinal adverse effects and poorer improvements in bone mineral density, compared with their brand-name counterparts. ${ }^{23,24}$

\section{Strengths and limitations}

In this study, we provided population-level data across an entire province for both the community and long-term care. We were able to describe the details for a 13-year period of therapy, representing more than 19 million dispensed prescriptions. However, there are some limitations in this study. One limitation is that our results may have limited generalizability because we reviewed records for drug dispensing in a single Canadian province that has universal health care and drug coverage for those aged 65 years and older. However, access to this large population with single-payer coverage allowed us to observe trends at a population level; with the exception of patients with private drug plans, because their data would not be captured in the ODB database. Another limitation is that we looked at the prescription rather than the patient level. This may have affected the trends, and may be the reason switches occurred faster in the long-term care setting where prescriptions are usually filled on a weekly cycle compared with the 90-day cycle in the community.

\section{Conclusion}

In summary, the automatic generic substitution policy used by the Ontario Drug Benefit leads to rapid uptake of generic osteoporosis drugs, creating an effective strategy to control drug costs. However, there seems to be an ongoing preference for brand-name oral bisphosphonates as indicated by a decrease in generic dispensing whenever a new brand-name drug becomes available. The reasons behind the shift toward new brand alternatives warrant further study. Similarly, studies comparing the effectiveness, tolerability and safety of generics are needed to ensure that the initial cost savings associated with widespread generic bisphosphonate use are not undermined later by increased health care costs.

\section{References}

1. Drivers of prescription drug spending in Canada. Ottawa: Canadian Institute for Health Information; 2011. Available: www.cihi.ca/cihi-ext-portal/pdf/ internet/drug_spend_drivers_en (accessed 2015 Feb. 25)

2. Aaserud M, Dahlgren AT, Kosters JP, et al. Pharmaceutical policies: effects of reference pricing, other pricing, and purchasing policies. Cochrane Database Syst Rev 2006;2:CD005979.

3. Generic drugs versus brand-name - What is the difference? Toronto: Canadian
Generic Pharmaceutical Association; 2014. Available: www.canadiangenerics .ca/en/resources/if_brandvsgeneric.asp (accessed 2015 Feb. 26).

4. Papaioannou A, Morin S, Cheung AM, et al. 2010 Clinical practice guidelines for the diagnosis and management of osteoporosis in Canada: summary. CMAJ 2010;182:1864-73.

5. Cadarette SM, Carney G, Baek D, et al. Osteoporosis medication prescribing in British Columbia and Ontario: impact of public drug coverage. Osteoporos Int 2012;23:1475-80.

6. Black DM, Cummings SR, Karpf DB, et al. Randomized trial of effect of alendronate on risk of fracture in women with existing vertebral fractures. Fracture Intervention Trial Research Group. Lancet 1996;348:1535-41.

7. Harris ST, Watts NB, Genant HK, et al. Effects of risedronate treatment on vertebral and nonvertebral fractures in women with postmenopausal osteoporosis: a randomized controlled trial. Vertebral Efficacy With Risedronate Therapy (VERT) Study Group. 7AMA 1999;282:1344-52.

8. Cadarette SM, Katz JN, Brookhart MA, et al. Comparative gastrointestinal safety of weekly oral bisphosphonates. Osteoporos Int 2009;20:1735-47.

9. Tadrous M, Wong L, Mamdani MM, et al. Comparative gastrointestinal safety of bisphosphonates in primary osteoporosis: a network meta-analysis. Osteoporos Int 2014;25:1225-35.

10. Ontario Drug Benefit Formulary/Comparative Drug Index. Edition 42. Toronto: Ministry of Health and Long-Term Care; 2014. Available: www.health .gov.on.ca/en/pro/programs/drugs/formulary42/edition_42.pdf (accessed 2015 Feb. 26)

11. Drug Interchangeability and Dispensing Fee Act. R.S.O. 1990, c. P.23. Available: www.e-laws.gov.on.ca/html/statutes/english/elaws_statutes_90p23_e.htm (accessed 2015 Feb. 26)

12. Sheehy $\mathrm{O}$, Kindundu $M$, Barbeau $M$, et al. Differences in persistence among different weekly oral bisphosphonate medications. Osteoporos Int 2009; 20:1369-76.

13. Ström O, Landfeldt E. The association between automatic generic substitution and treatment persistence with oral bisphosphonates. Osteoporos Int 2012; 23:2201-9.

14. Himmel $W$, Simmenroth-Nayda A, Niebling $W$, et al. What do primary care patients think about generic drugs? Int 7 Clin Pharmacol Ther 2005;43:472-9.

15. 2011 Census Data. Population and dwelling count data tables grouped by geography: Canada, provinces and territories. Ottawa: Statistics Canada. Available: www12.statcan .ca/census-recensement/2011/dp-pd/index-eng.cfm (accessed 2015 Feb. 26).

16. Burden AM, Huang A, Tadrous $M$, et al. Variation in the days supply field for osteoporosis medications in Ontario. Arch Osteoporos 2013;8(1-2):128.

17. Levy AR, O'Brien BJ, Sellors C, et al. Coding accuracy of administrative drug claims in the Ontario Drug Benefit database. Can 7 Clin Pharmacol 2003; 10:67-71.

18. The safety and effectiveness of generic drugs. Ottawa: Health Canada; 2012. Available: www.hc-sc.gc.ca/hl-vs/iyh-vsv/med/med-gen-eng.php (accessed 2015 Feb. 26).

19. Generic drug savings in the US. Fifth annual edition: 2013. Washington: Generic Pharmaceutical Association; 2013. Available: www.gphaonline.org/media/ cms/2013_Savings_Study_12.19.2013_FINAL.pdf (accessed 2015 Feb. 26).

20. Nightengale SL. Therapeutic equivalence of generic drugs: letter to health practitioners. Silver Spring (MA): US Food and Drug Administration; 1998. Available: www.fda.gov/Drugs/DevelopmentApprovalProcess/HowDrugsareDeveloped andApproved/ApprovalApplications/AbbreviatedNewDrugApplicationANDA Generics/ucm073182.htm (accessed 2015 Feb. 26).

21. Kesselheim AS, Bykov K, Avorn J, et al. Burden of changes in pill appearance for patients receiving generic cardiovascular medications after myocardial infarction: cohort and nested case-control studies. Ann Intern Med 2014; 161:96-103.

22. Kesselheim AS, Misono AS, Shrank WH, et al. Variations in pill appearance of antiepileptic drugs and the risk of nonadherence. $7 A M A$ Intern Med 2013;173:202-8

23. Ringe JD, Moler G. Differences in persistence, safety and efficacy of generic and original branded once weekly bisphosphonates in patients with postmenopausal osteoporosis: 1-year results of a retrospective patient chart review analysis. Rheumatol Int 2009;30:213-21.

24. Kanis JA, Reginster JY, Kaufman JM, et al. A reappraisal of generic bisphosphonates in osteoporosis. Osteoporos Int 2012;23:213-21.

Affiliations: Department of Medicine (Fraser), University of Western Ontario, London, Ont.; Leslie Dan Faculty of Pharmacy (Albaum, Tadrous, Burden, Cadarette), University of Toronto, Toronto, Ont.; Institute for Clinical and Evaluative Sciences (ICES) (Shariff, Cadarette), London, Ont.

Contributors: Lisa-Ann Fraser, Andrea Burden, Salimah Shariff and Suzanne Cadarette contributed to the conception and design of study. Jordan Albaum, Mina Tadrous and Andrea Burden acquired and analyzed the data. Lisa-Ann Fraser drafted the manuscript. Jordan Albaum, Mina Tadrous, Andrea Burden, Salimah Shariff and Suzanne Cadarette critically revised the manuscript. All of the authors interpreted the data, approved the final version submitted for publication and agreed to act as guarantors of the work. 
Funding: Lisa-Ann Fraser and Salimah Shariff were supported by the ICES, Western site, London, Ont. The ICES is funded by an annual grant from the Ontario Ministry of Health and Long-Term Care (MOHLTC). Core funding for ICES Western is provided by the Academic Medical Organization of Southwestern Ontario (AMOSO), the Schulich School of Medicine and Dentistry (SSMD), Western University, and the Lawson Health Research Institute (LHRI). The opinions, results and conclusions are those of the authors and are independent from the funding sources. No endorsement by ICES, AMOSO, SSMD, LDFP, LHRI or the MOHLTC is intended or should be inferred.
Acknowledgements: The authors acknowledge Racquel Jandoc who completed the analysis for this study at the Institute for Clinical Evaluative Sciences (ICES), University of Toronto (UofT) site, and the Leslie Dan Faculty of Pharmacy Dean's Fund that supported the ICES UofT analyses for this study.

Supplemental information: For reviewer comments and the original submission of this manuscript, please see www.cmajopen.ca/content/3/1/ E91/suppl/DC1 